\title{
Simultaneous transthoracic intervention for multiple cardiac defects in children
}

\author{
Guo-Liang Lu ${ }^{1 \#}$, Ting Sun ${ }^{2 \#} \wedge$, Jie-Zhou Huang ${ }^{1}$, Shao-Bo Xie ${ }^{1 \wedge}$ \\ ${ }^{1}$ Department of Cardiovascular Surgery, The First Affiliated Hospital of Guangzhou Medical University, Guangzhou, China; ${ }^{2}$ Department of \\ Ultrasonography, The First Affiliated Hospital of Guangzhou Medical University, Guangzhou, China \\ Contributions: (I) Conception and design: GL Lu, T Sun, SB Xie; (II) Administrative support: SB Xie; (III) Provision of study materials or patients: \\ SB Xie; (IV) Collection and assembly of data: GL Lu, T Sun, JZ Huang; (V) Data analysis and interpretation: GL Lu, T Sun, JZ Huang; (VI) \\ Manuscript writing: All authors; (VII) Final approval of manuscript: All authors. \\ \#These authors contributed equally to this work. \\ Correspondence to: Shao-Bo Xie. Department of cardiovascular Surgery, The First Affiliated Hospital of Guangzhou Medical University, No. 151 \\ Yanjiang west Road, Guangzhou 510120, China. Email: xieshaobo2015@163.com.
}

Background: Transthoracic intervention for isolated congenital heart disease (CHD) has been well tested for its technological feasibility and is increasingly used in clinical practice. We aimed to present our experience in simultaneous transthoracic intervention for multiple cardiac lesions in a series of pediatric patients.

Methods: Between March 2015 and December 2019, 20 patients with multiple CHD were referred to this study; mean age was $18.8 \pm 8.6$ (range, 4-36) months. The transthoracic echocardiography (TTE) diagnosis was atrial septal defect (ASD) and perimembranous ventricular septal defect (pmVSD) in 7 patients, patent ductus arteriosus (PDA) and ASD in 6, pmVSD and PDA in 2, pmVSD and valvular pulmonary stenosis (PS) in 2, ASD and PS in 2, and doubly committed subarterial VSD (dcsVSD) and PS in 1 patient. These patients underwent simultaneous transthoracic interventions with transesophageal echocardiography guidance. The procedure sequence was $\mathrm{PS} \rightarrow \mathrm{VSD} \rightarrow \mathrm{PDA} \rightarrow \mathrm{ASD}$. Electrocardiography and TTE were scheduled at discharge and follow-ups.

Results: All patients were occluded successfully without any thoracotomy conversion. Operation time was 56-120 (mean, 75 \pm 13 ) minutes. A 1.5-2.0-cm median sternum incision was performed in 6 ASD\&PDAs, 2 ASD\&PSs, and $1 \mathrm{dcsVSD} \& P S$. In 11 other patients, a $1.5-2.0-\mathrm{cm}$ incision in the inferior sternum was made and the chest closed with a drain. There were no serious complications before discharge and at follow-up.

Conclusions: Simultaneous transthoracic intervention for multiple cardiac defects in children is feasible with good short-term outcomes. For different lesions, the appropriate surgical incision and operational sequence can render the intervention minimally invasive and safer.

Keywords: Transthoracic intervention; multiple cardiac defects; children

Submitted Jul 18, 2020. Accepted for publication Nov 03, 2020.

doi: $10.21037 /$ tp-20-202

View this article at: http://dx.doi.org/10.21037/tp-20-202

^ ORCID: Ting Sun: 0000-0001-7004-6352; Shao-Bo Xie: 0000-0003-3599-7413. 


\section{Introduction}

Multiple cardiac defects are not rare in children with congenital heart disease (CHD). Historically, these were usually addressed with surgery. Although conventional open-heart repair with cardiopulmonary bypass (CPB) has been considered the standard treatment, recurrent respiratory tract infection and congestive heart failure are still risk factors for operative procedure, and the long midline incisions might lead to increased postoperative physical and psychological complications $(1,2)$. With the advent of newer technologies and expertise, transcatheter treatment has evolved as an alternative option. However, the technique is limited in infants because of the small diameter of their blood vessels and is not acceptable for transcatheter intervention, and radiation exposure is still a disturbing problem for children (3). Transthoracic intervention is a new technology that combines the advantages of transcatheter intervention and traditional surgery. The treatment for isolated CHD has been well tested for its technological feasibility and is increasingly used in clinical practice. However, Transthoracic intervention for multiple CHDs, obviates the need for surgery or a multistaged interventional procedure with prolonged fluoroscopy time, has been reported in only a few studies $(4,5)$. Therefore, we present our experience with simultaneous transthoracic interventions for multiple cardiac defects in children.

We present the following article in accordance with the STROBE reporting checklist (available at http://dx.doi. org/10.21037/tp-20-202).

\section{Methods}

\section{Patient enrollment}

Between March 2015 and December 2019, 133 patients were admitted to our center with multiple CHD and were allocated to groups on the basis of the surgical method selected by the patient. Patients with other malformations requiring surgical repair under $\mathrm{CPB}$ and patients with severe aortic valve or atrioventricular valve regurgitation were excluded. A group consisted of 20 patients who underwent an attempt of simultaneous transthoracic intervention were referred to this study. They were all clinically recommended for device closure or balloon valvuloplasty. These numbered 15 males and 5 females, with a mean age of $18.8 \pm 8.6$ (range, 4-36) months and a mean weight of $8.3 \pm 2.5$ (range, $4.8-12.5$ ) $\mathrm{kg}$. The transthoracic echocardiography (TTE) diagnosis before surgery was atrial septal defect (ASD) and perimembranous ventricular septal defect (pmVSD) in 7 patients, patent ductus arteriosus (PDA) and ASD in 6, pmVSD and PDA in 2, pmVSD and valvular pulmonary stenosis (PS) in 2, ASD and PS in 2, doubly committed subarterial VSD (dcsVSD), and PS in 1 patient. Other 113 patients who refused device closure received conventional surgical repair with $\mathrm{CPB}$. The study was conducted in accordance with the Declaration of Helsinki (as revised in 2013). The study was approved by the Ethics Committee of The First Affiliated Hospital of Guangzhou Medical University (No. GYFYY-2014-23), and written informed consent was obtained from the parents or guardians of all patients.

\section{Procedures}

The procedures underwent by these patients included ASD closure, VSD closure, PDA closure, and pulmonary valvuloplasty. Under endotracheal intubation and general anesthesia, transesophageal echocardiography (TEE; Philips IE33, Philips Medical Systems, Andover, MA, USA) was carried out at the beginning of the procedure and further estimates made of the cardiac abnormalities. The midesophageal (ME) four-chamber view, ME long-axis view, ME aortic valve short-axis view, upper-esophageal aortic arch long- and short-axis views showed the diameter of defects and surrounding structures. The size, location, and tissue rim of the defects and pulmonary valve annulus size is important in estimating the suitability of the transthoracic intervention. After making a $1.5-2.0-\mathrm{cm}$ median sternum incision or inferior sternum incision, $1 \mathrm{mg} / \mathrm{kg}$ heparin was administered to the patient. A purse-string suture was placed on the free wall of the right ventricle (RV) or the lateral wall of the right atrium (RA), which was precisely localized using TEE and palpation of the thrill. The technical details regarding closure of the VSD, ASD, PDA, and the pulmonary valvuloplasty procedure have been described in previous reports (6-8). The strict procedure sequence of occlusion was $\mathrm{PS} \rightarrow \mathrm{VSD} \rightarrow \mathrm{PDA} \rightarrow \mathrm{ASD}$, with TEE guidance and ensuring that each device was successfully positioned without any residual shunt or impingement of the atrioventricular valves. Finally, the purse string was tied and the procedure terminated. Upon occlusion failure or in case of complete atrioventricular block, the patient's incision was lengthened, and open-heart surgery was performed under cardiopulmonary bypass.

All patients with device implantation received antibiotics 


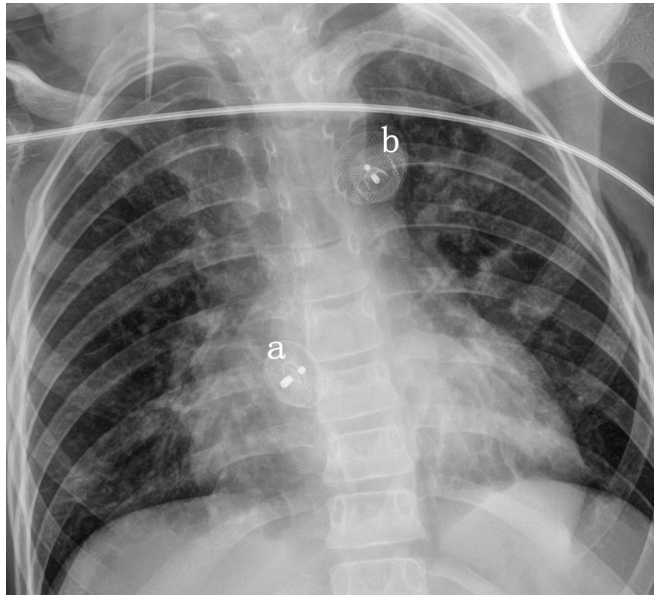

Figure 1 Chest X-ray shows atrial septal occluder (a) and patent ductus arteriosus occluder (b).

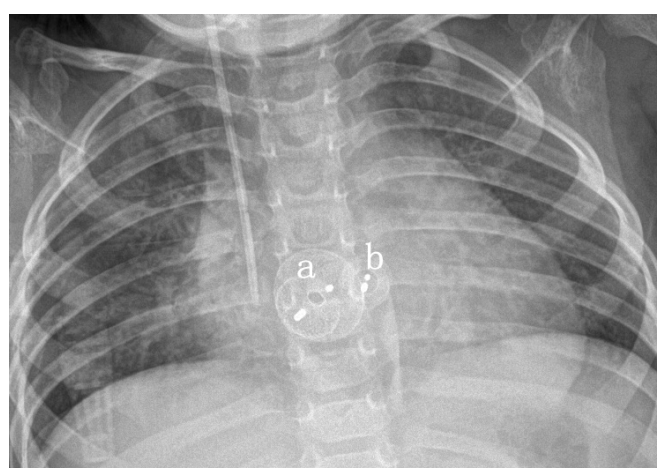

Figure 2 Chest $\mathrm{X}$-ray shows atrial septal occluder (a) and ventricular septal occluder (b).

during the operative procedure (cefuroxime sodium, $30 \mathrm{mg} / \mathrm{kg}$ ) and the following day (cefuroxime sodium, $100 \mathrm{mg} \cdot \mathrm{kg}^{-1} \cdot \mathrm{d}^{-1}, \mathrm{q} 8 \mathrm{~h}$ ). Oral aspirin (dose, $3-5 \mathrm{mg} / \mathrm{kg}$ ) was prescribed for 6 months to children with an occluder device. Chest X-ray was performed after surgery (Figures 1,2). Physical examination, including of the nervous system, and electrocardiography, TTE were scheduled at discharge, 3, 6, 12 months, and yearly thereafter during follow-up.

\section{Statistical analysis}

Data are expressed as the mean \pm standard deviation for continuous variables and as percentages for nominal variables. Differences between groups were compared using unpaired, 2-sided Student $t$-tests for continuous variables. $\mathrm{P}<0.05$ was considered statistically significant.

\section{Results}

Twenty cases were occluded successfully without any thoracotomy conversion. Patients' demographic and lesion characteristics are summarized in Table 1. TTE imaging of defect diagnose and the corresponding device are shown in Figure 3. On TTE, the mean size of VSDs was 3.3-5.5 (mean, $4.7 \pm 0.7$ ) $\mathrm{mm}$, and that of ASDs was 5.0-10.0 (mean, $7.4 \pm 1.5) \mathrm{mm}$. PDAs measured 4.0-6.0 (mean, 4.9 \pm 0.8 ) $\mathrm{mm}$ on TTE. The mean systolic pressure gradient across the pulmonary valve was $58-70$ (mean, $62.6 \pm 4.9$ ) $\mathrm{mmHg}$. The anesthesia time and operation time were 130-200 (mean, 158 \pm 22 ) minutes and 56-120 (mean, 75 \pm 13 ) minutes respectively. The amount of intraoperative blood loss was $0.7-6.9$ (mean, $3.3 \pm 1.9$ ) $\mathrm{mL} / \mathrm{kg}$. The length of postoperative ventilation ranged from 0.3 to 4 (mean, $2.2 \pm 1.3$ ) hours with postoperative hospital stay ranging from 2 to 8 (mean, $5.5 \pm 1.6)$ days. In 15 patients complicated with secundum ASD, the diameter of the Amplatzer septal occluder was 10-16 (mean, $12.1 \pm 1.8) \mathrm{mm}$. The diameter of the VSD occluder was $5-8$ (mean, $6.8 \pm 0.9$ ) $\mathrm{mm}$, as 11 pmVSDs were closed with a symmetric occluder and $1 \mathrm{dcsVSD}$ with an asymmetric occluder. A total 8 PDAs were closed with an Amplatzer duct occluder; the size was $8-10 \mathrm{~mm}$ in 5 patients and $6-8 \mathrm{~mm}$ in 3 patients. Five patients complicated with PS underwent successful pulmonary valvuloplasty using cristal balloons; the size was $15 \mathrm{~mm}$ in 2 patients, $16 \mathrm{~mm}$ in 1 , and $18 \mathrm{~mm}$ in 2, resulting in reduction of the gradient across the valve to $\leq 30 \mathrm{mmHg}$. In 11 patients, a $1.5-2.0-\mathrm{cm}$ inferior sternum incision (Figure 4) was made and the chest closed with a drain. A $1.5-2.0 \mathrm{~cm}$ median sternum incision (Figure 4C) was made in other 6 cases of ASD\&PDA, 2 of ASD\&PS, and in $1 \mathrm{dcs} V S D \& P S$.

Other 113 patients with multiple congenital cardiac defects were corrected by cardiac surgery. Both time of anesthesia and time of surgery, length of postoperative ventilation and length of postoperative hospital stay were significantly shorter in the intervention group compared with the $\mathrm{CPB}$ group $(\mathrm{P}<0.05)$. A comparison of two groups is presented in Table 2.

The follow-up period ranged from 5 to 56 (mean, $25.2 \pm 16.1$ ) months. All patients showed good growth and development. Data of TTE were available for all patients and indicated the absence of residual shunts and geometry reconstruction of the heart. There were no deaths, no complete atrioventricular block, no hemolysis, no stroke event, no intracardiac infection, no occluder detachment or displacement, or other complications during hospitalization 
Table 1 Patients' demographic information and lesion characteristics

\begin{tabular}{|c|c|}
\hline & Outcome \\
\hline Male & 15 \\
\hline Female & 5 \\
\hline Mean age (months) & $18.8 \pm 8.6$ (range, $4-36)$ \\
\hline Mean weight (kg) & $8.3 \pm 2.5$ (range, $4.8-12.5$ ) \\
\hline Co-morbidities & 9 \\
\hline Prematurity & 1 \\
\hline Respiratory tract infection & 7 \\
\hline Mediterranean anemia & 1 \\
\hline Previous interventions & None \\
\hline Previous drug therapy & None \\
\hline VSD & 12 \\
\hline Diameter (mm) & $3.3-5.5($ mean, $4.7 \pm 0.7)$ \\
\hline Closure diameter (mm) & $5-8($ mean, $6.8 \pm 0.9)$ \\
\hline pmVSD & 11 \\
\hline dcsVSD & 1 \\
\hline Secundum ASD & 15 \\
\hline Diameter (mm) & 5.0-10.0 (mean, $7.4 \pm 1.5$ ) \\
\hline Closure diameter (mm) & $10-16$ (mean, $12.1 \pm 1.8$ ) \\
\hline PDA & 8 \\
\hline Diameter (mm) & $4.0-6.0$ (mean, $4.9 \pm 0.8)$ \\
\hline Closure diameter (mm) & $8-10[5] ; 6-8$ [3] \\
\hline Valvular PS & 5 \\
\hline Balloon size (mm) & 15 [2]; 16 [1]; 18 [2] \\
\hline Inferior sternum incision & 11 \\
\hline $\mathrm{pmVSD}+\mathrm{ASD}$ & 7 \\
\hline $\mathrm{pmVSD}+\mathrm{PDA}$ & 2 \\
\hline $\mathrm{pmVSD}+\mathrm{PS}$ & 2 \\
\hline Median sternum incision & 9 \\
\hline$A S D+P D A$ & 6 \\
\hline$A S D+P S$ & 2 \\
\hline dcsVSD + PS & 1 \\
\hline
\end{tabular}

VSD, ventricular septal defect; pmVSD, perimembranous VSD; dcsVSD, doubly committed subarterial VSD; ASD, atrial septal defect; PDA, patent ductus arteriosus; PS, pulmonary stenosis. and the post-operation period.

\section{Discussion}

Congenital heart defects are common birth defects and patients with complex CHD account for 2.5/1,000 to 3/1,000 live births (9). The first case of simultaneous treatment of an ASD and balloon dilation of valvular PS was reported in 1997 by Yip et al. who treated a 7-yearold girl with transcatheter intervention (10). Transthoracic intervention, a hybrid technique for isolated CHD has been widely used in the past decades, associated with no age or weight limitation, shorter distance and directional performance, decreased surgical morbidity, shorter duration of hospital stay, and avoidance of radiation exposure and issues with satisfactory vascular access (11-13). Moreover, with the real-time echocardiography monitor, the operative process can be better observed and guided. Once the device fails or procedure unsuccessful, it can be easily converted to conventional surgery with CPB (14). Of course, the new technology still has its limitations. It must be performed under general anesthesia with tracheal intubation. And its minimally invasion has been questioned (15). Based on this initial successful experience, we found that in dealing with multiple cardiac defects simultaneously, transthoracic intervention is a feasible and safe procedure with satisfying early results in children. We believe that this hybrid technique may involve staged therapy for complex CHD in the future.

Effective and safe transcatheter interventions are considered viable alternatives to surgical closure. At our institution, transthoracic intervention for isolated CHD has been performed since August 2013, and more than 1,200 patients have successfully undergone implantation. However, the procedure for multiple CHDs is not simple a combination of what is used in isolated CHDs. The choice of incision is the first step and this is also a crucial step in the operation. Based on a literature review, most clinical practitioners report using an inferior sternum incision (Figure $4 A$ ) and left second intercostal incision (Figure $4 B$ ) for transthoracic intervention $(4,16)$. Normally, the free wall of the RV is exposed via a minor inferior sternum incision for the closure of a pmVSD, with a shorter distance and directional performance can vertically advance the delivery sheath across the VSD. However, for a dcsVSD, ASD\&PDA, ASD\&PS, or PDA\&PS, it is usually necessary to extend the inferior sternum incision or make the intercostal incision. Therefore, we recommend a median 


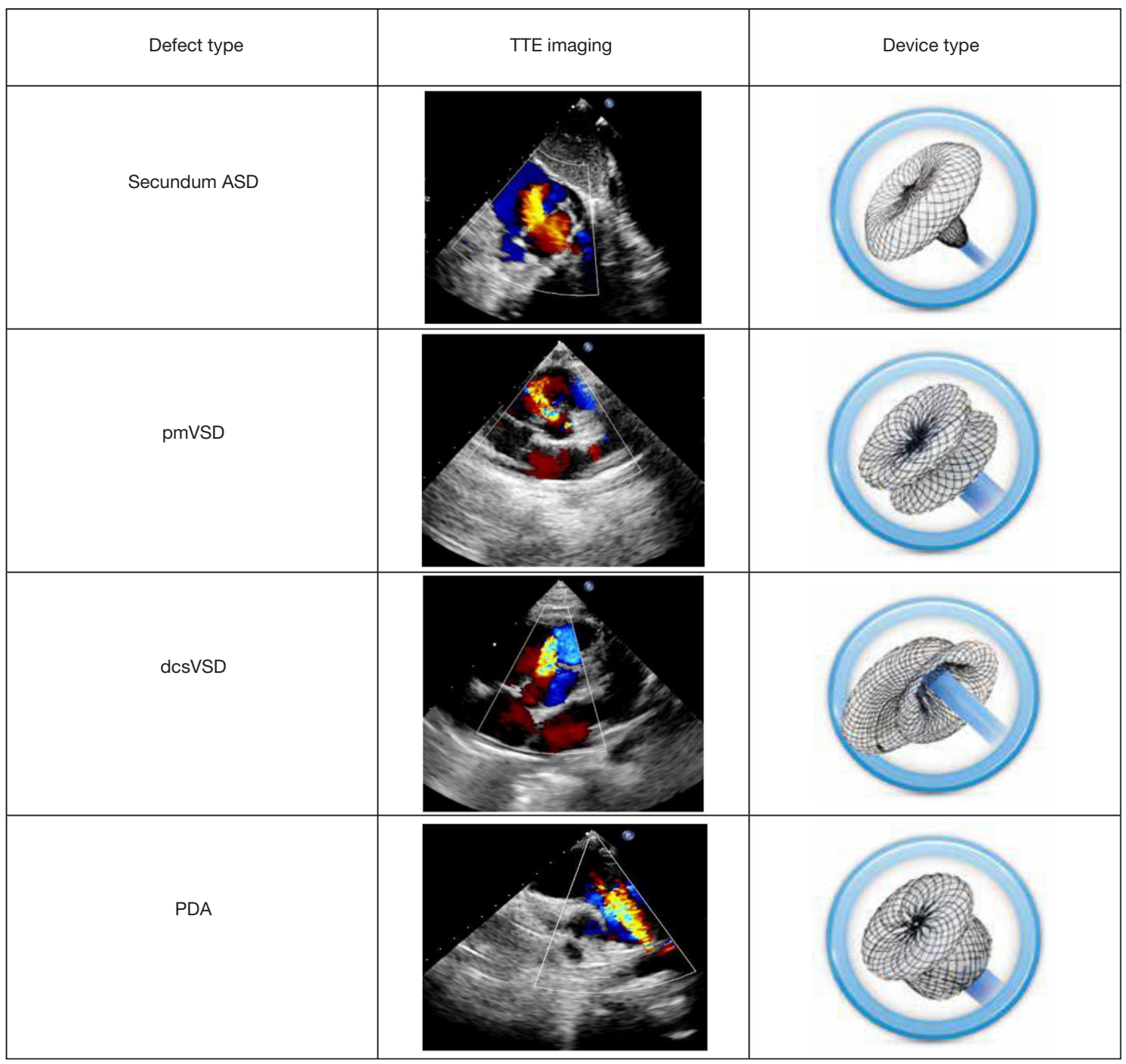

Figure 3 TTE imaging of defect diagnose and the corresponding device are shown. ASD, atrial septal defect; VSD, ventricular septal defect; pmVSD, perimembranous VSD; dcsVSD, doubly committed subarterial VSD; PDA, patent ductus arteriosus.

sternum incision (Figure 4C) for these patients. Technically, a traction stitch can be placed through a $1.5-2-\mathrm{cm}$ incision, such as at the third rib level, and pulled left or right down to the right ventricular outflow tract or RA, which is exposed with the assistance of a retractor. This provides a shorter delivery path and more flexible handling, with the sheath perpendicular to the plane of defects rather than through the inferior sternum incision. Moreover, the operational details via a median sternum incision are similar to those through a left intercostal incision, ensuring the integrity of the chest, and reducing pain and the likelihood of thoracic deformity post operation. However, if the closure fails, a minor median sternum incision is more easily converted to conventional open-heart surgery than a left intercostal incision.

Standardization of the operational order in simultaneous interventions remains a controversial topic in clinical practice. Hu et al. recommend the procedure sequence of occlusion VSD $\rightarrow \mathrm{ASD} \rightarrow \mathrm{PDA} \rightarrow \mathrm{PS}$ (4). However, the common view among Chinese medical experts for intervention treatment of compound congenital cardiac anomalies is the sequence $\mathrm{PS} \rightarrow \mathrm{VSD} \rightarrow \mathrm{PDA} \rightarrow \mathrm{ASD}(17)$. As is known, VSD occlusion leads to the most complications, and the failure incidence of CHD declines from highest to lowest in the order $\mathrm{VSD} \rightarrow \mathrm{PDA} \rightarrow \mathrm{ASD}$. The simple principle to follow is, "the most difficult first, then the 

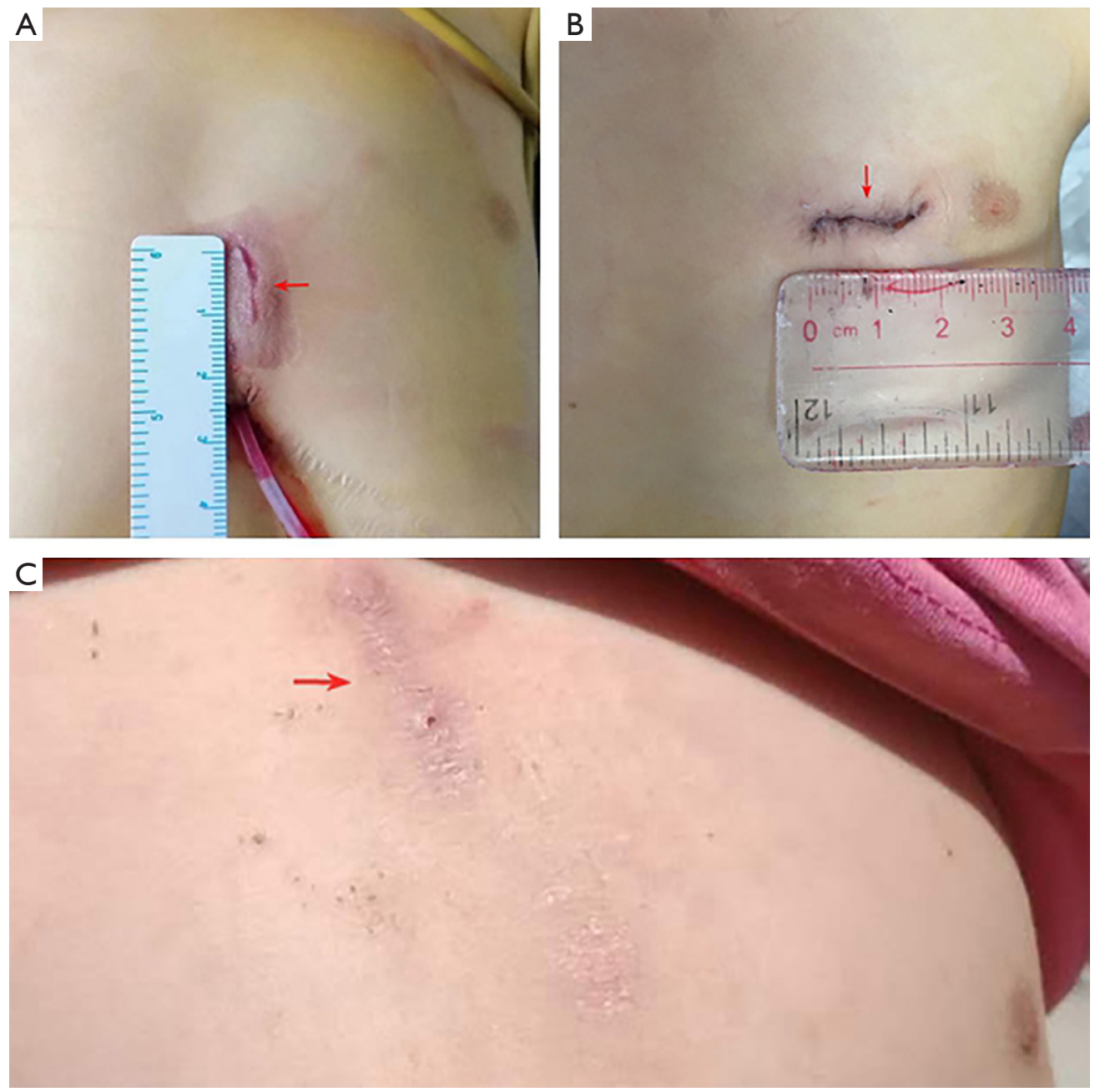

Figure 4 Different surgical incisions: inferior sternum incision (A), intercostal incision (B) and median sternum incision (C).

Table 2 Comparison of clinical outcomes in both groups

\begin{tabular}{|c|c|c|c|c|c|c|c|}
\hline & $\begin{array}{l}\text { Time of anesthesia } \\
\text { (minutes) }\end{array}$ & $\begin{array}{l}\text { Time of surgery } \\
\text { (minutes) }\end{array}$ & $\begin{array}{l}\text { Postoperative } \\
\text { ventilation (hours) }\end{array}$ & $\begin{array}{l}\text { Postoperative } \\
\text { hospital stay (days) }\end{array}$ & $\begin{array}{l}\text { Intraoperative } \\
\text { blood loss (mL/kg) }\end{array}$ & $\begin{array}{l}\text { Postoperative } \\
\text { pneumonia (n) }\end{array}$ & $\begin{array}{l}\text { Blood } \\
\text { transfusion (n) }\end{array}$ \\
\hline Intervention & $158 \pm 22$ & $75 \pm 13$ & $2.2 \pm 1.3$ & $5.5 \pm 1.6$ & $3.3 \pm 1.9$ & 1 & 0 \\
\hline$P$ value & $<0.001$ & $<0.001$ & 0.03 & 0.02 & $<0.001$ & 0.59 & $<0.001$ \\
\hline
\end{tabular}

Values are mean \pm standard deviation. CPB, cardiopulmonary bypass.

easiest" or "the most complex first, then the simplest". However, in pulmonary valvuloplasty or defect closure, the question remains as to which should be performed first. In theory, correcting the defects first will diminish the shunt volume subsequently reducing the gradient across the pulmonic valve (18). And, there was a fear of acute congestive heart failure and pulmonary edema as a result of increased pulmonary blood flow into previously protected pulmonary artery circulation (19). However, when both PS and defects coexist, left-to-right shunting is prevented if right ventricular pressures suddenly increase owing to the outflow obstruction caused by the pulmonary valvuloplasty 

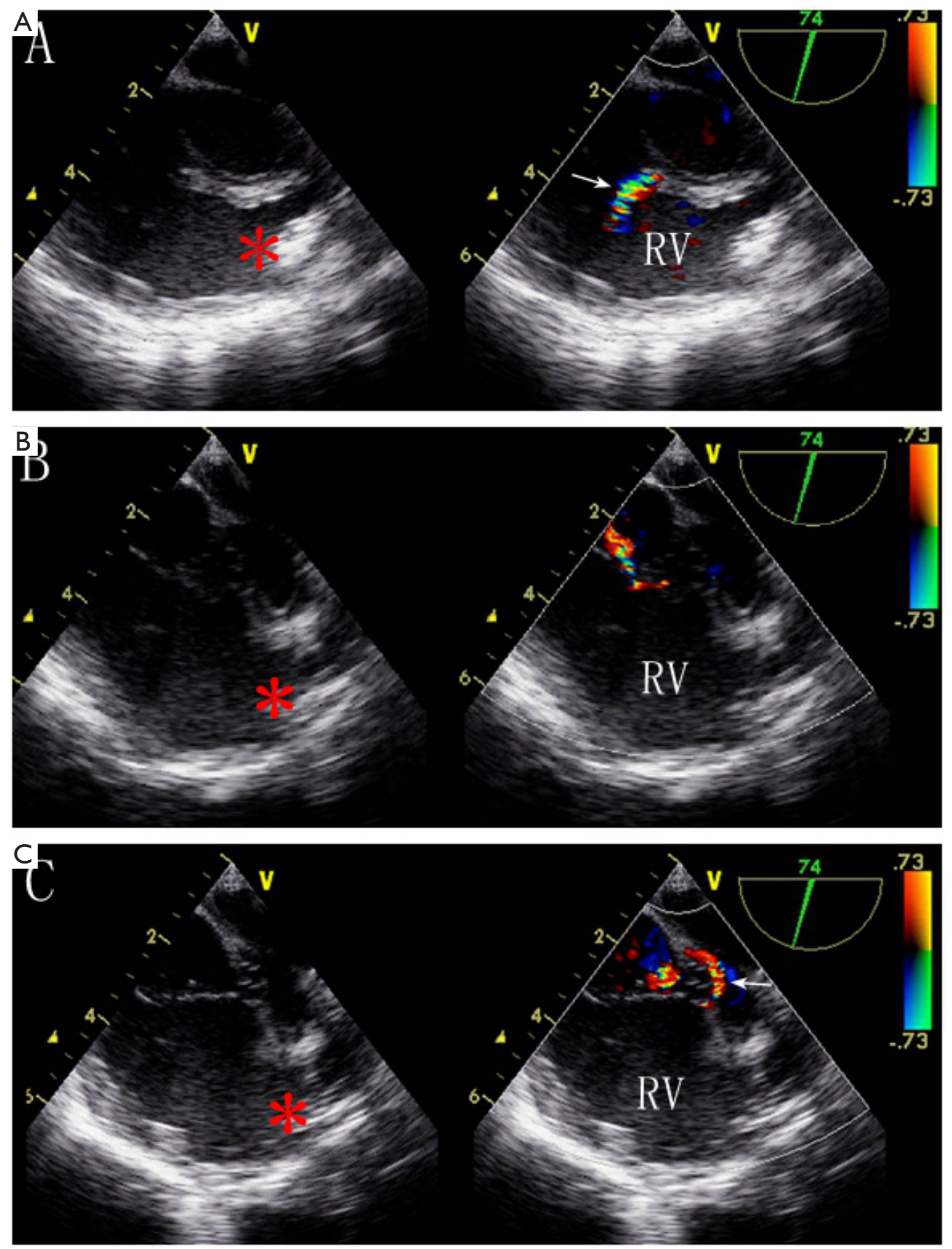

Figure 5 Transesophageal echocardiography (TEE) shows the procedure of perimembranous ventricular septal defect and valvular pulmonary stenosis (pmVSD\&PS). A left-to-right shunting $(\rightarrow)$ confirmed using color Doppler ultrasound as the pulmonary balloon $\left(^{*}\right)$ is in "close" (A). The left-to-right shunting was reduced (B) and even temporarily became right-to-left shunting (C) with the pulmonary balloon in "open" $\left.{ }^{*}\right)$. RV, right ventricle.

(Figure 5). Moreover, from a technical view, performing a balloon valvuloplasty prior to deployment of an occluder device would limit the possibility of potentially dislodging the device (20). Careful review of the hemodynamic data is critical in the clinical decision-making strategy, and $\mathrm{PS} \rightarrow \mathrm{VSD} \rightarrow \mathrm{PDA} \rightarrow \mathrm{ASD}$ may be the most widely acceptable 
sequence.

However, the costs of simultaneous transthoracic interventions for multiple cardiac defects are twice as much as those of traditional surgery. At our center, only about $15 \%$ of patients are willing to undergo the new procedure. We need to do more in the future, such as establishing available funds, minimizing costs, and expanding publicity of this option.

\section{Conclusions}

This initial study demonstrates that simultaneous transthoracic intervention for multiple cardiac defects in children is technically feasible, with excellent procedural and short-term outcomes. For different lesions, the appropriate surgical incision and operational sequence can render the intervention minimally invasive and safer. Additional studies including more patients and long-term outcomes are needed.

\section{Acknowledgments}

Funding: None.

\section{Footnote}

Reporting Checklist: The authors have completed the STROBE reporting checklist. Available at http://dx.doi. org/10.21037/tp-20-202

Data Sharing Statement: Available at http://dx.doi. org/10.21037/tp-20-202

Peer Review File: Available at http://dx.doi.org/10.21037/tp20-202

Conflicts of Interest: All authors have completed the ICMJE uniform disclosure form (available at http://dx.doi. org/10.21037/tp-20-202). The authors have no conflicts of interest to declare.

Ethical Statement: The authors are accountable for all aspects of the work in ensuring that questions related to the accuracy or integrity of any part of the work are appropriately investigated and resolved. The study was conducted in accordance with the Declaration of Helsinki (as revised in 2013). The study was approved by the Ethics Committee of The First Affiliated Hospital of Guangzhou
Medical University (No. GYFYY-2014-23), and informed consent was taken from the parents or guardians of all patients.

Open Access Statement: This is an Open Access article distributed in accordance with the Creative Commons Attribution-NonCommercial-NoDerivs 4.0 International License (CC BY-NC-ND 4.0), which permits the noncommercial replication and distribution of the article with the strict proviso that no changes or edits are made and the original work is properly cited (including links to both the formal publication through the relevant DOI and the license). See: https://creativecommons.org/licenses/by-nc-nd/4.0/.

\section{References}

1. Rose EA. Off-pump coronary artery bypass surgery. $\mathrm{N}$ Engl J Med 2003;348:379-80.

2. Gessler P, Schmitt B, Pre'tre R, et al. Inflammatory response and neurodevelopmental outcome after openheart surgery in children. Pediatr Cardiol 2009;30:301-5.

3. Sun WF, Dong ZF, Gong K, et al. Transcatheter closure with use of the SHSMA occluder in 180 patients with congenital heart defects: preliminary results. Tex Heart Inst J 2010;37:531-7.

4. Hu S, Yang Y, Zhu Y, et al. Experience with percardiac interventions for multiple congenital heartdiseases in children. Interact Cardiovasc Thorac Surg 2014;19:812-5.

5. Hongxin L, Zou CW, Liang H, et al. Intraoperative device closure of multidefect under transoesophageal echocardiographic guidance in an infant. Eur Heart J Cardiovasc Imaging 2012;13:715.

6. Zhu P, Sun Y, Yang Q, et al. Intraoperative device clo sure of atrial septal defects with minimal transthoracic invasion: a single-center experience. Tex Heart Inst J 2013;40:256-60.

7. Ou-Yang WB, Wang SZ, Hu SS, et al. Perventricular dev ice closure of perimembranous ventricular septal defect: effectiveness of symmetric and asymmetric occluders. Eur J Cardiothorac Surg 2017;51:478-82.

8. Zhao T, Yang Y, Xu X, et al. Transesophageal echoca rdiographic guidance of percardiac device closure of intracardiac defects in patients weighing less than $10 \mathrm{~kg}$. J Card Surg 2012;27:740-4.

9. Hoffman JI, Kaplan S. The incidence of congenital heart disease.J Am Coll Cardiol 2002;39:1890-900.

10. Yip WC, Chan KY, Godman MJ. Simultaneous transcatheter valvuloplasty and Amplatzer septal occlusion 
for pulmonary valve stenosis and secundum atrial septal defect. Ann Acad Med Singapore 1998;27:578-81.

11. Wen Z, Xu M, Chun Z, et al. Transthoracic occlusion for patent ductus arteriosus. J Cardiovasc Pulm Dis 2011;30:325-7.

12. Xing Q, Pan S, An Q, et al. Minimally invasive perventricular device closure of perimembranous ventricular septal defect without cardiopulmonary bypass: Multicenter experience and mid-term follow-up. J Thorac Cardiovasc Surg 2010;139:1409-15.

13. Zhu P, Qiang HF, Liu F, et al. Clinical evaluation of percutaneous and intra-operative device closure of atrial septal defects under transesophageal echocardiographic guidance: one center experience and mid-term follow-up. J Cardiothorac Surg 2020;15:20-8.

14. Chen Q, Cao H, Chen ZY, et al. Comparative study of the transcatheter and transthoracic device closure treatments for atrial septal defect: A Chinese single-institution experience. Medicine (Baltimore) 2017;96:e6316.

15. Xie S, Fang J, Yang C, et al. Percutaneous trans-jugular vein closure of atrial septal defect with steerable introducer under echocardiographic guidance. J Thorac Dis

Cite this article as: Lu GL, Sun T, Huang JZ, Xie SB. Simultaneous transthoracic intervention for multiple cardiac defects in children. Transl Pediatr 2021;10(1):112-120. doi: 10.21037/tp-20-202
2015;7:1850-3.

16. Liu L, Zhao TL, Yang YF, et al. Intraoperative device closure of subaortic ventricular septal defects. J Card Surg 2013;28:456-60.

17. Committee on Congenital Heart Diseases, Internal Medicine Branch of Cadiovascular Diseases, Chinese Physicians' Association. Interventional treatment of common congenital heart diseases: the common view of Chinese medical experts. Part Five-Transcatheter intervention for the treatment of compound congenital cardiac anomalies. J Interv Radiol 2011;20:345-51.

18. Vera JA, Nounou M, Kern M. Staged percutaneous atrial septal defect closure and pulmonic balloon valvuloplasty in an adult. Catheter Cardiovasc Interv 2008;72:416-23.

19. Ardakani MB, Haddadzadeh M, Rajaei S. Simultaneous Transcatheter Closure of Ventricular Septal Defect and Pulmonary Valvuloplasty. Iran J Pediatr 2012;22:555-8.

20. Wahl A, Windecker S, Misteli M, et al. Combined percutaneous pulmonary valvuloplasty and atrial septal defect closure for pulmonary valvular stenosis and associated secundum atrial septal defect in an adult. Catheter Cardiovasc Interv 2001;53:68-70. 